\title{
Para se desopilar o fígado: aporias e soluções ao se traduzir Alphonse Allais ${ }^{*}$
}

\author{
Alexandre Prudente Piccolo ${ }^{\dagger}$
}

Rire, c'est se sentir supérieur.

Marcel Schwob

Resumo: Depois de traduzidos quase trinta crônicas/contos de Alphonse Allais, extraídos de coleções variadas do autor, apresento um breve panorama de seus textos e algumas de suas estratégias discursivas na produção de efeitos cômicos; ademais, discuto certas aporias ao se traduzirem determinadas passagens, bem como soluções que julgo adequadas na versão para o português.

Palavras-chave: Alphonse Allais; Literatura francesa; Texto humorístico; Humor; Comicidade; Século XIX.

Abstract: Having translated to Portuguese almost thirty Alphonse Allais' French chronicles/ short-stories, taken from different book collections of the author, I present a brief overview of his texts and some of his discursive strategies on producing comic effects; afterwards, I argue some aporias when translating certain passages, as well as some solutions I do believe suitable in Portuguese.

Keywords: Alphonse Allais; French literature; Humorous text; Humor; Comicality; $19^{\text {th }}$ century.

\footnotetext{
${ }^{*}$ Cumpre registrar minha gratidão ao Prof. Dr. Luiz Dantas (in memoriam), à Mélanie Leroux e à J ulie Wetterwald, que, em ocasiões e de modos diferentes, me ajudaram tanto a entender sutilezas do texto francês de Allais, quanto a revisar as traduções que propus ao português.

† Doutorando em Linguística (Área de Letras Clássicas) no IEL-Unicamp. Email: alexandrepiccolo@gmail.com.
} 
Piccolo, Alexandre Prudente - Para se desopilar o fígado: aporias e soluções ao se traduzir Alphonse Allais

Após idas e vindas com traduções, realizadas em momentos diversos, de pequenos textos (crônicas, contos, editoriais...) de Alphonse Allais, me vi compelido tanto a refletir sobre algumas das estratégias de humor que pude evidenciar nesses textos, quanto a comentar dificuldades e soluções encontradas no processo tradutório. Não pretendi classificar as traduções em termos de seu sucesso ou eficácia, noções certamente variáveis, sobretudo em se tratando de textos de caracteres, ao mesmo tempo, literário e humorístico. Assim, apresento algumas de minhas alternativas tradutórias, ciente de serem apenas uma(s) dentre um amplo leque de possibilidades.

A fim de evitar que as análises e as observações pareçam soltas, artificiais, ou exclusivamente técnicas e cerradas em elementos linguísticos, primeiramente se faz uma resumida apresentação do autor, de seus textos e principais traços característicos, além de sua acolhida em volumes brasileiros, bem como se comenta, a seguir, algum pano de fundo teórico, no intuito de auxiliar a discussão da tradução, particularmente da tradução de cunho literário e, ainda mais especificamente, da tradução de humor. Creio que o cruzamento dessa particularidade, humor mais literatura (talvez melhor, literatura mais humor), foi relevante não apenas para a redação deste ensaio, como para o equilíbrio das traduções propostas.

\section{Um pouco sobre "esse tal" Allais}

Alphonse Allais nasceu em Honfleur em outubro de 1854, pequena cidade portuária na Normandia. "Filho de um farmacêutico a quem deveria suceder, não tardou Allais a deixar-se absorver pela vida boêmia de Paris, fazendo parte sucessivamente dos grupos fantasistas dos Hidropatas, dos Hirsutos e do Gato Preto," anotam Paulo Rónal e Aurélio BuARQue (1999: 271). Em meio a um agitado cenário cultural (a famigerada Belle Époque), mesmo antes de se dedicar a suas publicações em periódicos, Allais se viu cercado de amigos literatos que se tornariam mais ou menos célebres na cena literária 
Piccolo, Alexandre Prudente - Para se desopilar o fígado: aporias e soluções ao se traduzir Alphonse Allais

francesa: Léon Bloy, Georges Courteline, Guy de Maupassant, Lautréamont, Villiers de I'Isle-Adam, Jules Renard, Gabriel de Lautrec, Charles Cros, entre outros). ${ }^{1}$ Escreveu centenas de contos, crônicas, editoriais e outros "textos curtos" publicados regularmente em jornais humorísticos parisienses, reunidos depois em antologias anthumes et posthumes. Por fim, negligenciadas as recomendações médicas, aos 51 anos Alphonse Allais morreu em Paris de embolia pulmonar.

Como resume J ean-Marc Defays (1992a: 28-9), os textos de Allais são, no início de sua produção, transcrição de gags, histórias improvisadas, monólogos para supostas encenações que depois vêm se rechear de desafios, mistificações, empréstimos carnavalescos - impulsos típicos do final do século XIX. Muitos desses textos não apenas narram histórias aparentemente engraçadas, porém (sob um ol har perscrutador) narram histórias em torno do modo como as histórias são feitas, na esteira do Tristam Shandy de Sterne, comparação emprestada de Eco (1986: 191). “Experimentador por vocação (...), ele manifesta em sua obra literária uma curiosidade sem limite aliada a um ceticismo sem remissão", mescla que, segundo DefaYs (1992b: 254), em alguma medida explica os extremos variados da comicidade de seus textos: "do espirituoso ao grotesco, da caricatura à ironia, da facécia ao absurdo."

De que os textos allaisianos cedo saíram das fronteiras francesas e aportaram em terras brasileiras, dá prova a breve menção feita por Lima Barreto em seu Isaías Caminha (1909). Ao explicar a Floc quem era o desconhecido Pierre Weber, diz a personagem Deodoro Ramalho, no romance brasileiro de 1909:

\footnotetext{
${ }^{1}$ Alguns desses autores possuem narrativas traduzidas nos volumes 4, 5 e 7 de Mar de Histórias (vide FERreira, A. B. de H. e RónAl, P. na bibliografia), acompanhadas de breves biografias. Vale apontar, no volume 7, o conto de COURTELINE "O cavalheiro que achou um relógio" dedicado a Alphonse Allais. O artigo de DefaYs (1992a) traça um bom panorama dessa fumisterie ("mistificação") literária.
} 
Piccolo, Alexandre Prudente - Para se desopilar o fígado: aporias e soluções ao se traduzir Alphonse Allais

- Oh! Não conheces?! É uma celebridade ultraparisiense, "parisianíssima"... Só lá pode haver destas... Nada de calhamaços, de coisas pantafaçudas e solenes; ligeireza, gauloiseries ["graçola licensiosa"], um quase tudo e um quase nada, como disse alguém... É dos cinco reis do espírito francês atual: ele, o Tristan Bernard, o Courteline, o Alphonse Allais... Nunca leste - Vous m'en direz tant dele e do Tristan Bernard? (BARRETO 1909: cap. X, p. 219)

Se os textos de Allais eram lidos por aqui já no começo do século XX, por uns poucos letrados da época, eram (provavelmente...) lidos no original como ainda muito influía a literatura francesa no período - e não em traduções.

As traduções de Paulo Rónai e Aurélio Buarque de Holanda, em Mar de Histórias (v. 7), de Flávio Moreira da Costa, em Os 100 melhores contos de humor da literatura universal, ${ }^{2}$ e de Attílio Cancian, no apêndice do volume Lector in Fabula, de Umberto Eco, são as únicas que encontrei para o

\footnotetext{
${ }^{2}$ Deixando de lado a idiossincrasia da seleção (diversas outras narrativas de Allais, a meu ver, são melhores que as duas selecionadas), cabe fazer aqui menos a mera crítica judicativa, como alerta José Paulo PAES (1990: 109 e ss.), que a analítica. Dou dois exemplos de problemas de interpretação e versão, apenas no conto "Uma Petição" (extraído do volume Pas de bile!, como não foi informado por F. M. da Costa). Além da paragrafação apresentar-se completamente diferente da original, logo na abertura se ignora um trocadilho importante no nome do protagonista: M. Onézime Lahilat > M. On exhume la hilare "Sr. Desenterre-se-AHilária", por exemplo, no lugar de grafá-lo exatamente como no original (e sem nota!).

No começo da narrativa, uma água fétida, lançada a esmo duma bacia na rua, acaba sujando as calças do protagonista, que passeava na calçada em frente uma funilaria. Diz o texto francês: Une femme d'un certain âge, la propre épouse du ferblantier cause de cette catastrophe, ne trouvait rien de mieux, en la fâcheuse occurrence, que de se tenir les côtes avec toutes ses mains disponibles.

Eis como traduz Flávio Moreira da Costa (grifo meu): “Uma mulher de certa idade, a própria esposa do funileiro, responsável pela catástrofe, não encontrou nada de melhor para fazer, frente a esse desagradável incidente, do que colocar todas as suas mãos disponíveis na cadeira."

Em francês, se tenir les côtes é expressão idiomática que significa "rir intensamente, com força, à beça" (CHOLLet e ROBERT 2008: 20). Pior do que ter inventado uma solução estapafúrdia (donde foi que o tradutor tirou "cadeira"? talvez quisesse dizer "anca, quadril" ou mesmo "bunda" ? e o que significa a expressão proposta em português?) foi ter deixado 0 leitor na mão, pois seu texto não diz que a mesma mulher que causou o infeliz incidente se põe a rir ruidosamente do pobre-coitado (cujo nome não é gratuito...), depois de Ihe ter sujado as calças. Claro, o texto de Allais ainda propõe o reforço avec toutes ses mains disponibles, o que dificulta ainda mais a tarefa dos tradutores. Mas isso não é motivo para invencionices (mesmo que passageiras) travestidas de tradução séria.
} 
Piccolo, Alexandre Prudente - Para se desopilar o fígado: aporias e soluções ao se traduzir Alphonse Allais

português do Brasil. Portanto, são todas já do último quarto do século XX. Não sei se há outras em Portugal.

Talvez o primeiro ponto importante digno de reflexão acerca da tradução de tais textos é a natureza da prosa de Alphonse Allais. Texto de humor e ao mesmo tempo literário, de alguma graça mas não propriamente uma piada, seus escritos nasceram como colunas variadas (ora editoriais, ora faits-divers, ora simples ficção) publicadas em jornais de humor, no embalo dos folhetins do século XIX, segundo a voga do entretenimento humorístico. Portanto, não eram verdadeiras piadas ou chistes, ainda que seja possível verificar técnicas semelhantes em operação. Como Freud (1969: 21) faz questão de destacar (na reflexão de Jean Paul Richter), a "brevidade é o corpo e a alma do chiste, sua própria essência" - e há de se admitir que o texto de Allais não é breve como costumam ser as piadas. Ao contrário, além de reunir parágrafos e parágrafos com comentários os mais diversos, que podem vez ou outra provocar algum sorriso, em seus textos percebe-se uma voz do narrador que comenta os acontecimentos, interage com o leitor, faz trocadilhos mais ou menos óbvios, tece comentários irônicos, propõe digressões estapafúrdias etc. Enfim, além de autoria e extensão que, grosso modo, não se encontram nos chistes corriqueiros, talvez se possa aproximar a graça do texto allaisiano ao "riso recôndito" de que fala RoSAS (2002), em que o efeito final não é bem a gargalhada, mas uma espécie de prazer do intelecto, certo riso "fino" ou "sutil."

Alguém poderia perguntar se há um jeito de rir próprio da segunda metade do século XIX, a que os textos de Allais (e muitos outros) parecem dar testemunho. A resposta seria tanto sim quanto não.

Sim porque inúmeros elementos de que falam seus textos são próprios daquele tempo, daquele espaço, daquela cultura (coches, clubes literários, bêbados de absinto, as ruas de Paris, a belle époque...), e excluir essa dimensão cultural de sua produção seria descaracterizá-la, já que certos efeitos de humor vinculam-se diretamente a esses elementos de época. Claro 
Piccolo, Alexandre Prudente - Para se desopilar o fígado: aporias e soluções ao se traduzir Alphonse Allais

que jamais se responderá ao questionamento imponderável "como um leitor contemporâneo de Allais lia tais gagues?", mas essa dúvida não nos impede que se ache graça em seus textos, a nossa maneira. ${ }^{3}$

E não porque também é possível dizer que, assim como se ria, no final do século XIX, de invencionices elétricas ou das correspondências de leitores aos periódicos (por exemplo...), hoje, mutatis mutandis, se ri do excesso de gadgets eletrônicos a nos circundar, bem como de emails de leitores aos portais na internet, das mensagens por celular e de outras "modernidades" que nos rodeiam. 0 específico de que se ria há décadas atrás pode também ser equiparado, grosseiramente, às especificidades hodiernas. Atenuadas diferenças e distâncias, de algum modo continua-se a rir de muitas das (mesmas) coisas que estão em discussão e debate na moderna vida cotidiana.

Tais ponderações ajudam a propor uma noção de estilo literáriotextual allaisiano, cujos elementos essenciais cabe ao leitor-tradutor identificar e, na medida do possível, preservar ao vertê-lo ao português. Tome-se a reflexão de George SteIneR (1982: 197) como um alerta não apenas dessa dificuldade, mas do impasse no ato tradutório:

Todo ato de tradução é precedido de um apriorismo; antecedem-no suposições de 'traduzibilidade', em geral não examinadas. Partimos do princípio de que o texto à nossa frente pode ser decifrado e transferido para outro idioma de maneira mais ou menos exaustiva.

Não quero postular que a tradução seja uma tarefa impossível, à fronteira de uma objeção apenas prejudicial (como lembra José Paulo Paes, "no entanto se traduz"). Entre, de um lado, a decifração, a interpretação e a transferência de um código-mensagem em direção a outro idioma e, de outro, a sacralização do duplo significante-significado (em suas diversas instâncias)

\footnotetext{
${ }^{3}$ Ao prefaciar o romance Messieurs les Ronds-de-Cuir, Marcel SCHWOB ([1893] 2006: 7) chega a dizer que obra cômica de Courteline, "une o cômico dos antigos à variedade de hilaridade que foi especial ao século XIX." Contudo, acrescenta, numa previsão não sem ironia, que, assim como os tiques da humanidade não são imutáveis e até os deuses mudam às vezes, haverá um tempo em que não mais se rirá.
} 
Piccolo, Alexandre Prudente - Para se desopilar o fígado: aporias e soluções ao se traduzir Alphonse Allais

como unidade intransponível, a prática tradutória deixa de lado esse impasse e prefere exercitar-se constantemente naqueles rituais. Quero, contudo, como leitor e tradutor de uns poucos textos de Alphonse Allais, destacar um conjunto de características textuais, algumas comuns à língua francesa, outras particulares à prosa allaisiana, que merecem atenção tanto na leitura do original quanto (especialmente!) na passagem ao português, não apenas para que se identifiquem e se preservem certos efeitos humorísticos e se consiga uma almejada funcionalidade cômica, mas sobretudo para que o texto traduzido possa, por meio de indícios diversos, ser percebido como característico daquele autor. Em outras palavras, ideal seria que se pudesse dizer, ao ler um conjunto de textos traduzidos: "Allais assim teria escrito, se tivesse escrito em português."

Tendo em consideração tais questões tradutórias, talvez se possa situar a prosa allaisiana entre duas colocações de RosAs (2002: 64): se, por um lado, há situações em que certas passagens precisam ser traduzidas 'literalmente', para que não se perca de vista a função literária do texto, momento em que a nota de rodapé se mostra indispensável, por outro, é possível garantir em determinadas passagens certa equivalência funcional na produção humorística, sem destoar traços que caracterizem literária ou culturalmente a produção do autor (talvez graças à simetria entre as línguas-culturas em jogo), garantindo, por último, a empatia do leitor com o texto. Resumidamente, caso os fatores culturais e linguísticos não representem um empecilho à transposição textual (será isso possível?), a tradução terá mais chance de sucesso. Portanto, cabe questionar que rouages ${ }^{4}$ de seu discurso são indispensáveis nessa translação do texto francês para sua versão portuguesa.

Dou exemplos. Alguma estranheza que se note na expressão francesa deve ser transposta, sempre que possível, ao texto em português. Em "A busca da desconhecida", o autor usa les îles loniennes ao invés de les îles

\footnotetext{
${ }^{4}$ Engrenagens, mecanismos; elementos constitutivos.
} 
Piccolo, Alexandre Prudente - Para se desopilar o fígado: aporias e soluções ao se traduzir Alphonse Allais

Grecques, mais convencional - mantenha-se, pois, "as ilhas jônicas". Traduzir obus pelo incomum "obus" (embora possa parecer rebuscado ou algo distante) em português, e não por "granada" (grenade), ajuda a preservar algo da bizarrice lexical por vezes encontrada em "Simples mal entendido" - e em outros textos de Allais. Nesse conto citado, notem-se 0 advérbio (extremamente expressivo) municipalement, ${ }^{5}$ a aliteração que descreve o pai da protagonista (un bien brave Badois, ma foi! balayait...), bem como as difíceis expressões une purée visqueuse (que denota tanto a miséria financeira quanto o "grude" do casal) ou o simples dinde (tanto a fêmea do peru quanto "bobalhona") para se referir à esposa. Em "Os dois Hidropatas", a batida dos fiacres é descrita pelo verbo trinquer, que resolvi por "se bater", ${ }^{6}$ perdendo um espirituoso "brinde" entre os supostos embriagados do começo da narrativa. Na abertura de "As misérias da vida conjugal", a mulher é descrita como um ser ostinée (ao invés de obstinée), reforçando na grafia errada (por três vezes repetida) a tal obstinação feminina. Allais brinca com o onomatopaico panpanpana ("toctoctocou") da batida na porta em "Inanidade da lógica". Certos substantivos peculiares como a classe dos "soldadistas" 7 em "Conto de Natal" ou os registros infantis "pernininhas" ${ }^{8}$ em "Grande inteligência de uma pequena cachorrinha", ou dodo ("soninho, sonequinha") em "As misérias da vida conjugal" ou susucre ("dodocinho") em "Contra os cachorros" conferem certa oralidade e dão tessitura característica a essa prosa literário-humorística. Nessa última narrativa, note-se o preciosismo literário ${ }^{9}$ I'huis de la courtisane para dizer a "porta (melhor: portela) da cortesã." Dentre inúmeros outros exemplos de tipos variados, que não raro

\footnotetext{
${ }^{5}$ Cf. o advérbio petropolimente, no conto "A nova Califórnia" de Lima Barreto.

${ }^{6}$ Trinquer (fam.): subir des désagréments, des pertes. (Rey 1998: 1363).

7 De pioupioutesques, de pioupiou, forma familiar para "soldado."

${ }^{8}$ De papattes, de patte, "pata" ou, mais informalmente, "perna."

${ }^{9} 0$ movimento literário francês da época é vastíssimo e, pode-se dizer, envolvia desde o retrato naturalista e "fiel" das personagens retratadas, enquadrando-as como figuras animalescas (na esteira de um Zola), até a preocupação formal exímia na escolha cuidadosa de cada palavra (note-se, por exemplo, um Mallarmé na poesia).
} 
misturam ao tom sério, de nuances que oscilam entre 0 antiquado e 0 nobre/ elevado, os registros coloquiais e familiares da prosa cotidiana.

Além dessa minúcia na expressão, o tom convencional dos escritores medíocres e os clichês - de que falam Aurélio e Rónal (1999: 272, grifo meu) devem ser também conservados quando assim identificados:

\begin{abstract}
Inconfundível é a fórmula do espírito allaisiano. Ele parte, em geral, de uma idéia grotesca e absurda, que vai desenvolvendo com seriedade imperturbável, no tom convencional dos jornais ou dos escritores medíocres, com larga profusão de clichês e lugarescomuns. (FERREIRA e RóNAl, 1999: 272)
\end{abstract}

Assim, creio que se deve, sempre que possível, conservar em português essa expressividade "exótica", e não ignorá-la e aplainá-la.

Enfim, tais elementos textuais e discursivos, que podem parecer banais à primeira vista, não apenas ajudam a compor um traço peculiar da prosa, em que 0 autor agencia seus efeitos de humor, como delineiam as características literárias que o individualizam na miríade de outros autores (ou discursos, se preferir).

\title{
Análise de alguns casos
}

O primeiro exemplo de chiste analisado por FreUd (1969: 25ss.) é o com a palavra 'familionariamente' (ou famillionär em alemão). ${ }^{10}$ Um caso de técnica similaríssima se verifica no conto "Contra os cachorros", quando Allais diz, tendo iniciado a narrativa com insultos à raça canina:

Une dame pleurarde et sentimenteuse interrompit ma diatribe Uma senhora chorona e sentimentirosa interrompeu minha diatribe

\footnotetext{
${ }^{10}$ Um resumo desse trecho pode ser encontrado em POSSENTI (2010: 153-6).
} 
Piccolo, Alexandre Prudente - Para se desopilar o fígado: aporias e soluções ao se traduzir Alphonse Allais

0 adjetivo sentimenteuse é cunhado usando-se a mesma técnica que Freud descreve para 'familionariamente', isto é, a "estrutura composta" resultante faz coincidir duas palavras distintas que partilham partes silábicas comuns. Assim, para sentimenteuse pode-se propor um quadro diagramático similar:

\author{
sentimentale \\ menteuse \\ sentimenteuse
}

Ora, com economia notável o narrador do texto allaisiano afirma que a senhora em questão é não só chorona, mas sobretudo sentimental e (portanto...) mentirosa (hipócrita, fingida etc.) - sentidos reunidos sob um único étimo. Claro que esse não é propriamente um caso de chiste como é o exemplo freudiano, ${ }^{11}$ mas a sutileza da "condensação acompanhada pela formação de um substituto" (FreUd 1969: 28) pode acabar provocando algum sorriso no leitor atento.

Felizmente, nesse caso, a solução em português consegue preservar 0 efeito da condensação, graças a certa simetria entre as palavras das línguas envolvidas (sentimentale $\sim$ sentimental; menteuse $\sim$ mentirosa).

Entretanto, nem sempre as expressões se transpõem tão regularmente ao português, pelo menos. Veja-se o caso de um parágrafo de uma única oração do conto "Simples mal entendido." Ainda apresentando a personagem Angeline, o narrador diz no início do texto:

Son teint pétri de lis et de roses m'alla droit au coeur. ${ }^{12}$

A dificuldade reside no final da frase: m'alla droit au coeur. Traduzida como cada palavra está grafada, obtém-se: "foi-me direto ao coração".

\footnotetext{
${ }^{11}$ A palavra cunhada, no caso de Freud, serve de fecho a uma curta declaração, conferindo corpo breve à piada. No caso do texto de Allais, a palavra cunhada é (mais) um adjetivo na descrição de uma personagem, numa narrativa que prossegue.

12 "Simple Malentendu". In: AlLaIS. À se tordre, p. 101.
} 
Contudo, a pronúncia de m'alla droit confunde-se com a do adjetivo maladroit,-e ("inábil, desajeitado, desastrado"). Assim, a leitura da frase poderia sugerir ao menos estes dois sentidos, que também se sobrepõem:

...m'alla droit au coeur.

...foi-me direto ao coração.

Son teint pétri de lis et de roses...

Sua tez impregnada de lírios e de rosas...

...: maladroit au coeur.

...: desastrada ao coração. ${ }^{13}$

Ao tentar condensar numa só frase a tradução, propus algo que rebaixa o registro do original, porém sugere, na pronúncia ligeira do período, sentidos que se complementam e se sobrepõem:

Sua tez impregnada de lírios e de rosas me foi... deu direto no coração.

Assim, a solução proposta apresenta a superposição de duas leituras distintas, uma que preserva um dos sentidos do original (a de "ir direto ao coração"), outra que propõe uma nova expressão subjacente, que dê conta (em alguma medida) do sentido de maladroit:

... me foi direto no coração $=\ldots$ deu direto no coração (repetição)

....me fo[i]deu direto no coração $\sim$...me fodeu... (alteração)

Está claro que os efeitos obtidos não são os mesmos: ao usar dois verbos em português ("foi" e "deu"), a solução distancia-se mot à mot do texto francês. Contudo, a solução parece dispensar (assim espero) notas de pé

\footnotetext{
${ }^{13}$ Acrescentei dois pontos nessa hipótese de leitura para reforçar uma elipse (ex.: foi, mostrou-se etc.). Todavia, foi preciso alterar, na tradução, o gênero em concordância na expressão (masc.: son teint e maladroit; fem.: "sua tez" e "desastrada").
} 
Piccolo, Alexandre Prudente - Para se desopilar o fígado: aporias e soluções ao se traduzir Alphonse Allais

de página que expliquem o trocadilho, já que propõe um outro, algo similar. A despeito da ligeira vulgarização no texto ou da afronta à "norma culta" ${ }^{14} \mathrm{em}$ português, a passagem pode ser compreendida (assim me parece...) com clareza e funcionar a contento no texto, preservando um quê da graça inicial. Eis como Umberto Eco enuncia:

Traduzir significa sempre "cortar" algumas das conseqüências que 0 termo original implicava. Nesse sentido, ao traduzir não se diz nunca a mesma coisa. A interpretação que precede cada tradução deve estabelecer quantas e quais das possíveis conseqüências ilativas que 0 termo sugere podemos cortar. (...) Mas a negociação nem sempre é uma tratativa que distribui perdas e ganhos com equanimidade entre as partes em jogo. Também posso considerar satisfatória uma negociação em que concedi à contraparte mais do que ela me concedeu e contudo, considerando meu propósito inicial e sabendo que já parti em condições de nítida desvantagem, considerar-me igualmente satisfeito. (ECO, 2007: 107)

Trocadilho de técnica similar se encontra em "O criminoso precavido." Ao invadir uma joalheria, o assaltante é surpreendido pelo dono da loja, um inocente paspalhão (tipo que talvez recordasse nosso 'português' das piadas). Mesmo tendo sido pego em flagrante, o ladrão consegue, sem perder a calma e com muita sagacidade, matar o proprietário que o apanhara. A frase final do conto funciona como uma espécie de gatilho para a graça da história, confirmando a esperteza (melhor: a precaução, anunciada no título) do gatuno. Entretanto, no meio da narrativa, por duas vezes se lê no texto francês a expressão sac ad hoc, que o leitor atento (e conhecedor do latim ad hoc) pode associar ao aspecto prevenido do ladrão, que, afinal, levara consigo uma bolsa 'especial' para guardar as joias roubadas. Ora, podem-se separar os sentidos (ao menos dois) sobrepostos na expressão da seguinte maneira:

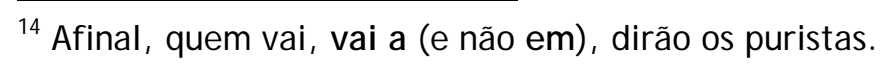


Piccolo, Alexandre Prudente - Para se desopilar o fígado: aporias e

1. $\operatorname{sac}$ ad hoc $=$ saco/ bolsa ad hoc (mantendo-se a expressão latina ad hoc, que funciona perfeitamente tanto no texto original quanto na tradução: o ladrão é precavido, traz consigo um saco ou uma bolsa previamente arranjada para isso, i.e. para guardar seu butim)

2. $\mathrm{sac}$ ad hoc $>\mathrm{sac}$ à dos $=$ mochila (considerando-se a pronúncia do conjunto: o ladrão traz consigo uma bolsa que, na verdade, é uma mochila, se pronuncia em francês como 'mochila'). Note-se que o "c" (de sac ad hoc) não é pronunciado nessa acepção, para se confundir com a pronúncia da palavra "mochila" em francês ('sác-a-dô').

Não consegui reunir num único composto em português os sentidos $1 \mathrm{e}$ 2 que a brincadeira allaisiana permite identificar em seu texto francês. Essa falha tradutória, por assim dizer, atesta-se na explicação que a nota de rodapé fornece ao leitor nesse caso. ${ }^{15}$

Outro recurso de que se vale Allais para criar pontos que condensam 0 riso em suas narrativas são os nomi parlanti de suas personagens, técnica que remonta às comédias de Plauto. ${ }^{16}$ Digo pontos que condensam porque, quando identificados, tais "nomes-trocadilhos" passam a direcionar a leitura do texto para o tema que deflagram. Um bom exemplo está no conto "Anestesia": apresentado o esbelto senhor Surgeon (personagem já sem um nome 'verdadeiro' no texto, graças à ignorância das empregadas), eis que aparece o vizinho, M. Lecoq-Hue. Ora, Allais simplesmente fantasia a pronúncia cocu ("corno, marido traído") ${ }^{17}$ sob outra forma gráfica, que à primeira vista parece realmente um nome próprio. Em suma, ele brinca com o nome da

\footnotetext{
${ }^{15}$ Dou outro exemplo de calemburgo que se vale de técnica semelhante e que embaraçou os tradutores e/ ou responsáveis pela legenda no filme Up in the air (2009; no Brasil: "Amor sem escalas"). A aeromoça se volta ao passageiro e pergunta: Do you want the can, sir? ("Quer a lata [de refrigerante], senhor?"). A legenda, ao optar verter a pergunta palavra por palavra, não consegue explicar a estupefação na cara de George Clooney, que fica visivelmente atordoado com a indagação. Ao ouvinte, o que se está perguntando é: Do you want the cancer?

16 Apenas para ilustrar, vejam-se, na comédia Aululária, os nomes Euclião ("bom escondedor"), Eunômia ("bem regrada"), Megadoro ("muito generoso"), Estáfila ("cacho de uva maduro" ) etc.

${ }^{17}$ Em "O humor é universal", POSSENTI (2010) comenta brevemente (a partir do prefácio de Pagnol) sobre o sucesso da figura do marido traído nas comédias francesas, e, por outro lado, o desconcerto dessa mesma personagem no mundo anglófilo.
} 
Piccolo, Alexandre Prudente - Para se desopilar o fígado: aporias e soluções ao se traduzir Alphonse Allais

personagem. Ao traduzir, adotei "Sr. X. Frudo" tentando emular um processo similar, mas não simétrico:

M. Lecoq-Hue $>$ lecoq[h]ue $>$ le cocu

Sr. X. Frudo $>$ xi[s]frudo $>$ chifrudo

A relação entre os significantes (fônico e gráfico) do nome e a característica da pessoa ${ }^{18}$ está no cerne da produção do humor na passagem que talvez possa, nesse caso, ser tomada como uma piada dentro do conto. Anunciado o nome do vizinho, o texto converge para a cena de adultério: 0 senhor X. Frudo, além de ciumento, é horrível de dar dó; o casamento entre 0 sr. X. Frudo e sua mulher é puramente financeiro, já que o ele é riquíssimo; sua esposa não se mostra satisfeita desde o dia em que se casaram; o dentista garboso e a senhora $X$. Frudo já demonstram interesse mútuo após alguns esbarrões fortuitos... quando ela tem a feliz ideia de ir ao dentista fazer uma consulta. Quando se chega ao desfecho, esse acaba se revelando menos risível que o trocadilho 'propulsor'. Salvo um ou outro breve comentário do autor ao longo do texto (que comento adiante), ainda é possível sustentar 0 calemburgo no nome da personagem como o chiste da história.

Em outra narrativa, no primeiro 'causo' da já citada "Contra os cachorros", Allais anuncia que seu amigo o visconde A. Bry d'Abbatut não partilha do anunciado repúdio aos cães. Ora, o nome A. Bry d'Abbatut, em sua forma abreviada do primeiro nome (A.) seguida de sobrenome (Bry) acompanhado da (suposta) região de procedência familiar (d'Abbatut), remonta a um título nobiliárquico, que o título de visconde apenas confirma. Entretanto, sua forma sonora evoca a expressão idiomática à bride abattue, equivalente à nossa "à rédea solta" (ou seja, "à vontade, livremente"). Assim, optei vertê-lo como "visconde R. É. de A. Souta", na tentativa de

\footnotetext{
${ }^{18}$ Veja-se POSSENTI (2010: 58) para algumas relações cômicas (à moda de piadas) entre o nome e a profissão das pessoas.
} 
Piccolo, Alexandre Prudente - Para se desopilar o fígado: aporias e soluções ao se traduzir Alphonse Allais

preservar o sentido de "rédea solta" velado sob uma técnica similar quanto à grafia de nomes e sobrenomes abreviados. Outra alternativa seria "visconde H. Lopes" (i.e. 'a galopes'), também uma boa opção pelo tom de brincadeira com o significante e o significado nome, ainda que se percam certas nuances de sentido. E vários outros casos similares podem ser apontados nos contos de Allais.

Outro de seus jogos diz respeito à própria materialidade do texto. Exemplifico: no segundo 'causo' do mesmo "Contra os cachorros", relata-se que um caval heiro casado, ao passear com seu cachorro, encontrou por acaso uma moça sedutora. E logo se entenderam. Quando chegam à casa dela (onde o cachorro é obrigado a ficar do lado de fora, por imposição da moçoila), diz o narrador, entre duas linhas de reticências:

Passagem proibida pela censura.

Lembre-se que, em "Um drama bem parisiense," o capítulo III da história é todo composto por linhas de pontos, conotando a reconciliação amorosa dos amantes que haviam se desentendido. ${ }^{19}$ Em "Uma alucinação", ao perceber que sua narrativa se arrasta lentamente, sem nenhum progresso, Allais propõe de súbito:

Uma linha de pontos para abreviar.

E assim o narrador avança sua história a seu bel prazer.

Claro que tais artimanhas não são por si só engraçadas, mas a maneira como 0 autor dos textos as agencia, intervindo abruptamente na cadência narrativa, acaba quebrando nossas expectativas como leitores, já que

${ }^{19}$ Cf. o capítulo LV das Memórias Póstumas, "O velho diálogo de Adão e Eva." 
Piccolo, Alexandre Prudente - Para se desopilar o fígado: aporias e soluções ao se traduzir Alphonse Allais

desarticula cursos regulares e previsíveis da história por meio dessas interrupções metatextuais. Como anota Defays (1992b: 256),

\begin{abstract}
desde o princípio, o enunciador não cessa de intervir à cada instante e de todas as formas em seu enunciado, para comentar seus dizeres ou os dos outros, para interpelar os protagonistas ou o leitor, para se perder em inumeráveis e intermináveis digressões. (...) Mais do que ser uma encenação, a enunciação é quase sempre projetada ao seio de um texto frutífero que se dispõe em diferentes patamares enunciativos. (DEFAYS 1992b: 256)
\end{abstract}

Note-se um outro exemplo de intervenção do narrador, logo na primeira oração do conto "Simples mal entendido". Depois do título, a primeira palavra do conto é "Angeline", protagonista da história, informação de que ainda não se sabe, na primeira leitura ingênua - na esteira de Eco (1986) -, mas que se supõe, tendo em vista que leitores (com alguma experiência) sabem que muitos contos começam assim, anunciando logo na abertura o nome do/ a protagonista. Eis que Allais continua com o parêntese "(já Ihes disse que ela se chamava Angeline?)." Para o leitor habituado aos procedimentos narrativos, esse parêntese é absurdo, por (pelo menos) dois motivos. Primeiro: o narrador ainda não disse nada da história, tão somente anunciou um nome, que se supõe de uma personagem; assim, não faz sentido que ele indague ao leitor acerca desse suposto esquecimento (que, na verdade, é um procedimento literário), já que não há nada na história que possa ter sido esquecido - o texto mal começou! Segundo: esse procedimento literário ou discursivo (i.e. o narrador confirmar, perguntando ao próprio leitor, se já anunciara uma informação importante, como o nome de uma personagem) pode e costuma, sim, acontecer em narrativas, sobretudo quando muitas coisas já foram contadas e descritas até o momento dessa intervenção; ora, até então no conto de Allais não se narrou absolutamente nada, a história encontra-se em sua primeira palavra! 0 parêntese, portanto, está "fora de lugar" e o leitor experiente consegue percebê-lo, usufruindo do clichê e da artimanha de Allais. 
Piccolo, Alexandre Prudente - Para se desopilar o fígado: aporias e soluções ao se traduzir Alphonse Allais

Essa mesma narrativa está recheada de diversas outras intervenções do autor, que chega a justificar seu comportamento inescrupuloso, ao final do conto, por meio dum parêntese cínico:

(Devo dizer, como minha desculpa, que esses fatos se deram no mês de um ano em que, depois de uma queda a cavalo, perdi todo senso moral. $)^{20}$

Em tempo: depois de uma queda a cavalo, costuma-se ficar descadeirado, pode-se perder a agilidade ou o bom equilíbrio de outrora, por causa de alguma fratura, por exemplo. Pode-se perder a carteira, o chapéu... Pode-se também perder os sentidos (i.e. ficar desacordado, desmaiado), que em francês se diz perdre conscience, perdre connaissance. ${ }^{21}$ Do absurdo de que se possa também perder um sentido específico, não uma percepção física, mas, sim, o julgamento de natureza moral após um tombo a cavalo, se vale o autor para produzir seu humor além-texto (lembre-se que esse parêntese funciona como uma espécie de confissão ao leitor), algo frequente em seus comentários no corpo dos contos.

Note-se como o narrador allaisiano brinca com as interpretações que seu leitor possa fazer de uma expressão dúbia. No já citado "Anestesia", assim diz a narrativa quando o senhor Surgeon e a senhora $X$. Frudo se encontram furtivamente na escada:

Toda vez, ele dizia consigo mesmo:

- Caramba!... está aí uma mulher com quem a gente não deve se entediar.

Toda vez, ela dizia consigo mesmo:

- Caramba!... está aí um homem com quem a gente não deve se entediar!

(Não garanto o teor escrupuloso dessa dupla expressão, mas posso assegurar o espírito exato. 22

\footnotetext{
20 "Simple Malentendu". In: ALLAIS. À se tordre, p. 104.

${ }^{21}$ Note-se a expressão popular tomber dans les pommes.

22 "Anesthésie". In: Allals. À se tordre, p. 116.
} 
Piccolo, Alexandre Prudente - Para se desopilar o fígado: aporias e soluções ao se traduzir Alphonse Allais

Em francês, ambos personagens usam on ne doit pas s'embêter, que traduzi como "a gente não deve se entediar". De qualquer maneira, é possível entendê-las como "eis uma pessoa interessante" até "eis alguém bom de cama", na fronteira do sentido sexual. Todavia o double propos ${ }^{23}$ a que se refere o parêntese fica também ambíguo para o leitor: pode se referir tanto às falas idênticas (repetidas, portanto, duplas) de cada personagem quanto à própria oscilação de sentido na expressão repetida on ne doit pas s'embêter: entre "eis alguém que não será chato/a" e a sugestiva noção "eis um(a) gostoso/ a...". Enfim, quando o narrador diz assegurar o espírito exato, nada de exato está assegurado aos olhos do leitor. Não se entenda aqui que o leitor é essencial ao sentido do texto, mas, sim, como diz Maingueneau (1996: 59), que o "texto [é] concebido como um dispositivo que organiza os percursos de leitura." É com essa oscilação propositalmente calculada que opera o texto allaisiano para lançar suas dúvidas, para produzir sua ambiguidade calculada, para sugerir seus efeitos humorísticos.

São dispositivos dessa ordem que o texto de Alphonse Allais faz questão de desarranjar, alterando os princípios da cooperação interpretativa, de que fala Umberto Eco (1986) ao esmiuçar alguns detalhes de Um drama bem parisiense segundo o viés da semiótica e da pragmática textual.

Outro conto que opera com estratégia semelhante é Os dois hidropatas. Ainda que muito se possa aproveitar das categorias propostas por Eco (por exemplo: um duplo Leitor-Modelo, certa sutileza textual que desacredita as anáforas narratológicas etc.) para também se analisar Os dois hidropatas, cabe apontar um detalhe cuja sutileza merece destaque: a presença (fática) do autor no texto, de maneira a desestruturá-lo. ${ }^{24}$

\footnotetext{
${ }^{23}$ Assunto/ comentário duplo, ambíguo.

${ }^{24}$ Por presença fática, entende-se o comparecimento do autor em determinado ponto da narrativa de modo a constituir uma ato de fala sua própria instância e permanência em determinada passagem discursivo.
} 
Piccolo, Alexandre Prudente - Para se desopilar o fígado: aporias e soluções ao se traduzir Alphonse Allais

O penúltimo parágrafo do conto é o único momento expresso da narrativa em que 0 autor intervém na história de modo incisivo, a ponto de abalar a confiança de seu leitor. ${ }^{25}$ No auge da narração, ou seja, quando se desej a confirmar que os dois envolvidos na batida são os mesmos personagens com que a história começa, entra em cena uma voz autoral (primeira pessoa), até então completamente ausente, que se posiciona no texto: J e m'approchai pour voir... ("Eu me aproximei para ver..."). Um autor intrometido se lança na narrativa, anuncia textualmente sua presença e acaba frustrando o leitor, que se viu enlaçado pela armadilha textual armada por Allais. Ainda que não propriamente interpelado, o leitor imerge na textualidade da narrativa e emerge, no desenlace do conto, ao mesmo tempo iludido e curioso para voltar a procurar (relendo o texto) seu "tropeço", enquanto se percebe logrado em sua leitura.

Note-se o sofisticado efeito que Allais alcança num trecho de "Uma mulherzinha bem moderna." Esposa ${ }^{26}$ e marido (novamente, feio e estúpido) viviam juntos na extrema pobreza. Ela, ambiciosa e gastadora; ele, naïf ("inocente, ingênuo") e dedicado. Uma noite, no quarto, conversavam ambos:

- Diga então, meu querido... diz ela passando suas mãozinhas delicadas nos reles cabelos do homem.

- Minha pequena?

- Você não sabe o que eu acabei de ler num jornal velho lá na saleta?

- 0 que então, minha querida linda?

- A história de um homem, em Versalhes, que fez um seguro de vida, e que recebeu o seguro apresentando para a Companhia um outro cadáver que o homem fez passar pelo dele.

- E então?

- Então, o homem recebeu o seguro.

\footnotetext{
25 Uma sutil insistência dos auxiliares no imparfait, denotando certa dúvida na expressão (il pouvait être neuf heures; ce devait être un signal), bem como a nomeação das personagens por meio de suas vestimentas poderiam ser duas estratégias listadas como espécies (diferentes, vale notar) de hipercodificação que sugerem ao leitor a tal desconfiança narratológica (Eco 1986: 174-5). Contudo, diferente de Drame..., em que há pontos variados de intervenção irônica dessa voz autoral, em Os dois hidropatas essa ocorrência não me parece tão incisiva.

${ }^{26}$ Note-se o oxímoro algo vulgar: une petite femme rudement gentille.
} 
Piccolo, Alexandre Prudente - Para se desopilar o fígado: aporias e soluções ao se traduzir Alphonse Allais

- Sim, mas ele foi pego?

- Ele foi pego, porque era um tonto. Mas eu, eu imaginei um truque fabuloso, para não ser pega.

$-! ! ! ? ? ?$

Nesse momento, eles sopraram a vela e eu não ouvi mais nada. ${ }^{27}$

0 narrador consegue, por meio dessa intromissão disparatada, ${ }^{28}$ deixar em suspenso o plano do casal, criando no leitor um misto de curiosidade e desacerto. Fica-se curioso (como leitor...) para saber o que a personagem fará para não ser presa, bem como ressabiado (idem...) para não cair nos mesmos ardis metatextuais do autor. Se o resultado final não é exatamente cômico, permanece um "sorriso bravo" em quem lê.

Uma paradoxal co-presença de autor e leitor no texto allaisiano, por outro lado, se nota especialmente em expressões corriqueiras como ditesvous, vous me direz que, vous récriez-vous etc. ${ }^{29}$ - como ressalta Defays (1992b: 257). Ainda que explícitas na cena enunciativa, permanecem amigáveis para o leitor e incômodas para o analista.

Em Chez Édison pode-se apontar duas vertentes frequentes dos textos de Allais: a anglofilia e o cientista-inventor. Por um lado, o universo anglófilo é explorado de maneiras diversas, seja por meio de nomes ingleses (que abundam em seus textos: bank-notes, Black and White, watering-place, surgeon etc.), seja para zombar dessa própria influência evidente no final do século XIX francês. Por outro, "a personagem do inventor ou do sábio

\footnotetext{
27 "Une petite femme bien moderne". In: AlLaIs. Le parapluie de l'escouade, p. 210-1.

${ }^{28}$ Claro, absurda e sem nexo segundo as convenções narratológicas e literárias tradicionais. Valendo-se de dispositivos enunciativos paradoxais (como, por exemplo: 1. anunciar-se no meio da cena narrada - ou, melhor, na intimidade dos personagens - quando a narração, até então, apresentara um narrador ausente e onisciente dos fatos relatados; 2. instaurar a dúvida narratológica por intermédio dessa mesma interrupção que, aos olhos do leitor, rompe com a onisciência narrativa; 3. declarar não pode mais ouvir suas próprias personagens porque não podia mais vê-los conversar - espécie de infração semiótica), o narrador escapa conscientemente de seu papel habitual e viola os critérios sobre os quais o leitor faz tanto suas exigências textuais quanto traça seu julgamento (estético, lógico, normativo etc.).

${ }^{29}$ Inclua-se o parêntese (vous ai-je dit qu'elle se nommait Angéline?) comentado acima.
} 
Piccolo, Alexandre Prudente - Para se desopilar o fígado: aporias e soluções ao se traduzir Alphonse Allais

distraído (...) é familiar ao leitor de Allais", como diz Defays (1992a: 30), que prossegue:

Os contemporâneos estão efetivamente fascinados pelas novas descobertas científicas e realizações técnicas que Ihes abrem esses horizontes fabulosos que eles exploraram lendo Júlio Verne. Os humoristas vão aí encontrar igualmente matéria para extrapolações e para invenções (...). E persiste indiferente durante a carreira de Allais essa paixão pelas invenções de todo tipo (...) que ele introduz em suas narrações misturando de modo inextrincável a lógica e o imaginário. (DEFAYS 1992a: 30)

No caso de Chez Édison, temos uma personagem tomada da vida real. 0 texto relata uma visita à casa do então célebre inventor norte-americano Thomas Edison, no chamado Orange Park. Tendo já desprezado a inventividade de um aparelho descrito como kinetógrafo (espécie de precursor do cinema), o autor prossegue sua narração descrevendo em detalhes a um suposto invento notável (em tom seríssimo): uma oil-lamp, ou melhor, uma lamparina. 0 que se acreditava aparentemente extraordinário acaba por se revelar ordinário e risível.

Uma pequena passagem, e que me pareceu difícil de ser traduzida para o português, encontra-se no final do texto. Eis seus parágrafos finais:

\footnotetext{
Malheureusement, la place me manque pour décrire toutes les merveilles d'Orange-Park. Pourtant, je ne veux pas passer sous silence un petit appareil bien simples, mais appelé à rendre de nombreux service.

Cet instrument se compose d'un fil se rattachant par chacune de ses extrémités à deux petites poignées en bois (wooden holders). Et c'est tout. Comme l'indique son nome: butter cutting thread, ce fil est un fil à couper le beurre.

Mais il est un instrument qu'Édison n'inventera jamais, car c'est un produit bien français, celui-là: c'est le fil à couper... dans les ponts.

Citoyens français, mes frères, nous sommes tous des daims! ${ }^{30}$
}

${ }^{30}$ Chez Édison. In: Allals. La Parapluie et I'escouade, p. 233-4. 
Piccolo, Alexandre Prudente - Para se desopilar o fígado: aporias e soluções ao se traduzir Alphonse Allais

Parece óbvio (mas é necessário esmiuçar o óbvio...), mas, depois de ter descrito (e com requinte!) uma lamparina, a expressão toutes les merveilles d'Orange Park soa realmente irônica. Ou seja, ela coloca em contradição aquilo que 0 autor diz ("são maravilhosas as invenções") e aquilo que ele quer dizer ("as invenções são pífias; melhor dizendo, engodo!"). Assim, ficam na imaginação do leitor as demais maravilhas inventadas por Édison, tomando-se por referência a lamparina descrita. A ironia é confirmada a seguir, quando Allais descreve um cortador de manteiga, tomando-o por uma invenção científica valiosa (à rendre de nombreux services).

A dificuldade de tradução surge quando 0 autor decide apresentar outra invenção - algo similar, é bem verdade - dessa vez creditada aos franceses: le fil à couper... dans les ponts. Em $\operatorname{argot}^{31}$ da época, a expressão couper dans [tous] les ponts significa croire à un mensonge, être crédule/dupe ("acreditar numa mentira/lorota, ser crédulo/otário"). Ao elaborar expressão fil à couper dans les ponts, Allais não só a relaciona ao invento que acabara de descrever (fil à couper le beurre), unindo-as formalmente pelo elemento fil à + [infinitif], mas sobretudo destaca que os franceses são crédulos e vivem acreditando em lorotas - dentre as quais, tomar as invenções de Édison como sérias ou dignas de crédito, como seu próprio texto acaba sugerindo.

A zombaria que Allais faz com seus compatriotas se confirma no parágrafo final, mais propriamente no insulto daims ("bobos, bestas"), também em argot. Num texto sério, sem piadas e brincadeiras, talvez fosse bem mais difícil fazer essa "crítica" que Allais faz com tanta ironia e bom humor. Ou, lembrando Cícero, "o gracejo e o riso dissolvem aquilo que não é fácil de ser diluído com argumentos." ${ }^{32}$

\footnotetext{
${ }^{31}$ Linguagem particular de pessoas que exercem a mesma função ou situam-se na mesma classe social; espécie de gíria ou calão, de uso informal.

${ }^{32}$ De oratore II, 236. Trad. Ivan Neves Marques J r., 2008, p. 48.
} 
Piccolo, Alexandre Prudente - Para se desopilar o fígado: aporias e soluções ao se traduzir Alphonse Allais

Entretanto, voltando à expressão: entendida a relação entre os "fios" ("fio de cortar manteiga" e fil à couper dans les ponts), fica a pergunta: como traduzir o segundo termo de maneira a dispensar uma nota explicativa?

Do ponto de vista do tradutor, melhores (no sentido de que "funcionarem mais facilmente") são os textos que se estruturam como uma piada ou um sketch cômico e que não dependem de algum trocadilho ou duplo sentido localizado numa formulação linguística, ${ }^{33}$ tampouco de detalhes geográficos, históricos ou culturais. Os tais poucos tópicos (independentes das especificidades de cada língua) de que falam as piadas, como propõe POSSENTI (1998: 44): preconceitos, assuntos proibidos, tabus etc.

Um exemplo (quase perfeito) desse tipo de texto é "As misérias da vida conjugal." Esse conto se vale do tópico "as esposas são irascíveis, briguentas e estão sempre mal humoradas ou irritadas com seus maridos" para brincar com a suposta felicidade da vida de casal. Resumidamente, quer o marido tenha chegado em casa cansado (cena 1), quer ele tenha chegado alegre (cena 2), sua esposa irá ralhar com ele. Além disso, ela sempre encontrará motivo para acreditar, esteja ele cansado ou contente, que ele não estava trabalhando (como o coitado alega irremediavelmente), mas, sim, traindo-a com outras mulheres. E as duas cenas se repetem invariavelmente durante toda a semana.

Mas não só. 0 conto faz também alusão ao ensaio (em diversas partes) de Balzac, Petites misères de la vie conjugale. Tome-se, por exemplo, a parte La logique des femmes, em que se começa desconstruindo uma ilusão: "se 0 senhor acredita ter se casado com uma criatura dotada de razão, o senhor está completamente enganado." O conto de Allais diz (antes de dizer que as mulheres são seres ostinados): “Diga azul na frente de certas senhoras, logo

\footnotetext{
${ }^{33}$ A título de provocação, como traduzir para outras línguas essas duas "piadinhas:"

1) Um amigo pergunta ao outro:

- Você sabe os motivos pelos quais os homens adoram as modelos?

- Sei-os.

2) Eterna dúvida: todo carteiro gosta de sê-lo?
} 
Piccolo, Alexandre Prudente - Para se desopilar o fígado: aporias e soluções ao se traduzir Alphonse Allais

elas afirmam vermelho. Convenha-Ihes vermelho, para Ihes agradar: verde! rugem na hora."

Pode-se bem supor que Allais esteja propondo adicionar um 'causo' à seleção de histórias do ensaio balzaquiano, ilustrando-o com mais uma cena da vida cotidiana. Contudo, ao invés de relatar casos distintos (com cores realistas, dizem os manuais da literatura), oferecendo um panorama multifacetado à vida conjugal do século XIX, como o faz Balzac, Allais prefere narrar apenas dois quadros cujos desfechos se equivalem, destacando a irascibilidade (irracionalidade?) da mulher casada.

Facilmente se pode cogitar que Allais coloca em cena(s) - literalmente - a proposição balzaquiana, extraída do ensaio mencionado: Un homme, quand il le voudrait, ne saurait discuter au lit avec sa femme: elle a trop d'avantages contre lui, et peut trop facilement le réduire au silence. ${ }^{34} \mathrm{Claro}$, sob um viés cômico, em que a mulher se vale, para tirar alguma vantagem sobre o marido, não de sua sensualidade ou sexualidade, mas de sua irritação permanente.

Entretanto, ainda que o jogo alusivo não seja percebido, o sketch funciona e bem, já que o tópico é comum e universal (por assim dizer...) e o texto acaba podendo ser lido aos moldes de uma piada.

\section{Conclusão? Não...}

Estaria Allais rindo a torto e a direito de seus leitores, a quem pode escapar a "sutileza" de seus jogos linguageiros? Das regras e dos procedimentos literários já estabelecidos? Da própria natureza da linguagem, tão propícia aos "desencontros cômicos"? Ou quer apenas divertir e entreter

\footnotetext{
34 “Um homem, quando quer, não conseguirá falar com sua mulher na cama: ela tem muitas vantagens contra ele, e pode muito facilmente reduzi-lo ao silêncio." "La logique des femmes (axiome)". In: BALZAC, H. de. Les petites misères de la vie conjugale.
} 
seus leitores (DefaYs 1992b: 258)? Teria sido Allais um enrustido pince-sansrire ("piadista que mantém 0 ar sério")?

Lembrando a formulação de SKINNER (2004: 21-2) - que resume a epígrafe de Marcel Schwob - "quando rimos, estamos frequentemente nos gabando ou glorificando diante de outra pessoa, por termos constatados que, comparadas conosco, elas sofrem de alguma fraqueza ou defeito desprezível." Então, de que se ria e se gabava Allais? Como lembra Eco (1986: 180), as enciclopédias se vingaram dele definindo-o como autor 'menor', uma vez que ele as questionou (ou riu delas, ao menos em relação ao funcionamento narratológico convencional dos textos). Como entender e explicar seu riso textual e metatextual? Ao se passarem seus textos ao português, continua-se também a rir com ele?

Eis as próprias indagações de Alphonse Allais, tão preocupado com questões similares às que impulsionam muitos estudiosos:

Pourquoi rit-on? Comment rit-on? Où rit-on? De quoi rit-on? Mir lit-on? $?^{35}$

Enfim, como diz uma das muitas frases espirituosas atribuídas ao próprio Allais: Ne nous prenons pas au sérieux, il n'y aura aucun survivant. ${ }^{36}$

\footnotetext{
${ }^{35}$ Frase de Allais extraída de Defays (1992b: 250): “Por que se ri? Como se ri? Onde se ri? De que se ri? GuerRlemos?" - seria uma possível tradução. Em francês, Mir é o nome de uma cidade na Rússia. Por sua vez, mirliton é uma espécie rudimentar de membrafone, instrumento de percussão que vibra, porém, por meio do sopro. E, last but not least, mi(r)lit on ( militons) pode ser entendido como "militemos, agitemos, façamos nosso pleito."

${ }^{36}$ Não nos levemos a sério, não haverá nenhum sobrevivente.
} 


\section{Referências bibliográficas ${ }^{37}$}

ALLAIS, A. À se tordre: histoires chatnoiresques. Édition du groupe 'Ebooks libres et gratuits'. Disponivel em: «ttp:/ / www. ebooksgratuits. com/ pdf/ allais_a_se_tordre. pdf >. (05/ 10/2011).

. Le parapluie de l'escouade: oeuvres anthumes. La bibliotèque électronique du Québec. Disponível em: বhttp:/ / beq. ebooksgratuits. com/ vents/ Allais-bec. pdf>. (05/ 10/ 2011).

BARRETO, L. Recordações do escrivão Isaías Caminha. Lisboa: Livraria Classica Editora, 1909. Disponível em: 〈http://www.brasiliana.usp.br>. (03/ 10/2011).

Chollet, I.; Robert, J.-M. Les expressions idiomatiques. Espagne: CLE International, 2008.

Courteline, G. Messieurs les Ronds-de-Cuir. Tableau-Roman de la vie de bureau. Éditions du Boucher, 2006 (10ed. 1839). Disponível em: «ttp:// www. leboucher.com>. (05/ 10/2011).

DefaYs, J-M. Alphonse Allais: la fumisterie littéraire, Romantisme. n. 75. Paris: CDU-SEDES, 1992a, pp. 27-34.

"Pour une pragmatique du discours comique". In: Revue romane. n. 27-2, Copenhague: 1992b, pp. 250-265.

Dictionnaire d'argot (arg. pop. fam.): Disponível em: «ttp:// www. languefrancaise. net/ bob/ >. (05/ 10/ 2011).

Eco, U. Lector in fabula: a cooperação interpretativa nos textos narrativos. Trad. Attílio Cancian. São Paulo: Ed. Perspectiva, 1986.

Quase a mesma coisa. Trad. Eliana Aguiar. Rio de Janeiro: Ed. Record, 2007.

FerReira, A. B. de H.; Rónal P. Mar de Histórias: antologia do conto mundial. v. 6. $4^{\mathrm{a}}$ ed. Rio de J aneiro: Nova Fronteira, 1999.

FREUD, S. "O chiste e sua relação com o inconsciente". In: Edição Standard Brasileira das Obras Psicológicas Completas de Sigmund Freud. v. VIII. Trad. C. Magalhães de Freitas e Isaac Izecksohn. Rio de Janeiro: Imago, 1969.

\footnotetext{
${ }^{37}$ Para as obras de Alphonse Allais, me servi de edições em arquivos eletrônicos disponíveis tanto na Bibliothèque électronique du Québec quanto no grupo Ebook libres et gratuits, edições em que não há propriamente uma "data de publicação". Contudo, ficam registrados os endereços dos arquivos para download, bem como de outros endereços eletrônicos relevantes neste artigo.
} 
Maingueneau, D. Pragmática para o discurso literário. Trad. Marina Appenzeller. São Paulo: Martins Fontes, 1996.

MARQUES J R., I. N. O riso segundo Cícero e Quintiliano: tradução e comentário de De Oratore, livro II, pp. 216-291 (De ridiculis) e da Institutio Oratoria, livro VI, 3 (De risu). São Paulo: Dissertação de mestrado USP, 2008.

MoReIRA DA COSTA, F. (org.) Os 100 melhores contos de humor da literatura universal. Rio de J aneiro: Ediouro, 2001.

PAES, J. P. Tradução, a ponte necessária: aspectos e problemas da arte de traduzir. São Paulo: Ed. Ática, 1990.

POSSENTI, S. Os humores da língua: análises lingüísticas de piadas. Campinas, Mercado de Letras, 1998. . Humor, língua e discurso. São Paulo: Contexto, 2010.

REY, A. Le Robert micro. Paris, Dictionnaires le Robert, 1998.

RoSAS, M. Tradução de humor: transcriando piadas. Rio de J aneiro: Lucerna, 2002.

Schwob, M. Essai de paradoxe sur le rire. In: Courteline, G. Messieurs les Ronds-de-Cuir. Tableau-Roman de la vie de bureau. Éditions du Boucher, 2006 (10ed. 1893). 〈http:// www.leboucher. com>. (05/ 10/2011).

SKINNER, Q. Hobbes e a teoria clássica do riso. Trad. Alessandro Zir. São Leopoldo: Ed. Unisinos, 2004.

SteineR, G. Uma arte exata. In: StelneR, G. Nenhuma paixão desperdiçada. Trad. Maria Alice Máximo. Rio de J aneiro: Ed. Record, 2001. pp. 197212. 